\title{
DANOS DE ADULTOS DE EPICAUTA ATOMARIA (GERMAR, 1821) EM PLANTAS DE FARINHA-SECA ( $\left.{ }^{(}\right)$
}

\author{
ANDRE LUIZ LOURENÇÃO $\left({ }^{2,4}\right)$, VICTOR PAULO DE OLIVEIRA $\left({ }^{3,4}\right)$ \\ e MARCO ANTONIO MILAN BOAVENTURA $\left({ }^{3}, 4\right)$
}

\begin{abstract}
RESUMO
Farinha-seca (Pithecellobium edwallii Hoehne) é uma árvore da família Leguminosae bastante utilizada no Estado de São Paulo para sombreamento da cultura do cacaueiro. Em outubro de 1982, ocorreu infestação de adultos de Epicauta atomaria (Germar, 1821) em plantas dessa leguminosa em lavouras paulistas de cacau. Nas regiôes infestadas, prncedeu-se à avaliação de dano em quatro localidades: Olímpia, Onda Verde, Tanabi e Pariquiera-Açu; is médias de desfolhamento, estimado visualmente em porcentagem de área foliar comida, foram respectivamente $32,0,20,2$, 17,2 e $20,5 \%$.
\end{abstract}

Termos de indexação: Epicauta atomaria (Germar, 1821); farinha-seca; Pithecellobium edwallii Hoehne; desfolhamento.

(1) Trabalho apresentado na 37ạ Reunāo Anual da Sociedade Brasileira para o Progresso da Ciência, realizada em Belo Horizonte (MG), de 10 a 17 de julho de 1985. Recebido para publicação em 18 de janeiro de 1984.

(2) Seção de Entomologia Fitotécnica, Instituto Agronômico (IAC), Caixa Postal 28, 13100 Campinas (SP).

$\left({ }_{4}^{3}\right)$ Seção de Plantas Tropicais, IAC.

( ) Bolsista do CNPq. 


\section{INTRODUÇÃO}

A cultura do cacaueiro necessita proteção contra o sol e ventos durante a sua formação, principalmente nos primeiros anos. No sombreamento inicial, podem ser utilizadas bananeira, mandioca, tefrósia (Tephrosia candida D.C.) e leucena (Leucaena glauca Benth.); já na arborização permanente, usam-se espécies de médio e grande porte da família Leguminosae, como Erythrina spp. e farinha-seca (Pithecellobium edwallii Hoehne), que, além de proporcionarem o sombreamento desejado, fixam o nitrogênio atmosférico, contribuindo para melhorar as condiçōes do solo (CORAL \& BRILHO, 1978). Em cultivos comerciais do Estado de São Paulo, é bastante comum o uso de farinha-seca.

Em outubro de 1982, ocorreu infestação de Epicauta atomaria (Germar, 1821) (Coleoptera: Meloidae) $\left.{ }^{5}\right)$ nessa leguminosa, em lavouras de cacau situadas em diversas regiōes paulistas. Esse coleóptero é praga polífaga (GALLO et alii, 1978; MARICONI, 1976), e foi observado alimentando-se em espécies vegetais das famílias Passifloraceae (MEDINA et alii, 1980), Amaranthaceae, Chenopodiaceae, Compositae, Convolvulaceae, Leguminosae (sem haver menção de $P$. edwallii), Malvaceae e, principalmente, Solanaceae (SILVA et alii, 1968). Adultos de E. atomaria realizam postura no solo, sendo os ovos, numerosos, aderentes uns aos outros; as larvas que deles eclodem são subterrâneas, podendo ser consideradas benéficas, pois predam ovos de gafanhotos e grilos (MARICONI \& ZAMITH, 1954). Após a fase de pupa, os adultos surgem ao ar livre. E nesse estádio que o inseto se torna nocivo, alimentando-se da folhagem das plantas.

\section{AVALIACÃO DOS DANOS}

Das regiōes paulistas infestadas, procedeuse à inspeção nos municípios de Tanabi, Pariqüera-Açu, Olímpia e Onda Verde; nas duas primeiras, as árvores de farinha-seca tinham cinco-seis anos de idade, e nas duas últimas, doistrês anos. Nos quatro locais, em dezembro de 1982, foi feito levantamento dos danos causados por E. atomaria, mediante estimativa da porcentagem de área foliar comida. Em cada município, avaliou-se uma lavoura, onde foram examinadas, ao acaso, vinte árvores; para cada uma, estimou-se visualmente o desfolhamento sofrido. Nota-se pelos resultados - Quadro 1 - que o ataque foi intenso nas quatro regiões, prejudicando de modo mais acentuado o sombreamento em Olímpia, cujas plantas, mais jovens, conseqüentemente, tiveram o crescimento mais prejudicado. Não foi adotada nenhuma medida de controle contra $o$ inseto nessas lavouras, $e$ as plantas se recuperaram satisfa-

$\left({ }^{5}\right)$ Os autores agradecem ao Dr. Richard B. Selander, University of Illinois, Urbana-Champaign, a confirmação da identidade do inseto. 
toriamente, com exceção de Olímpia, onde a recuperação foi apenas parcial. Em março de 1983, ocorreu nova infestação do inseto, porém em níveis populacionais mais baixos, nas lavouras inspecionadas em Tanabi e Olímpia. Neste último local, em setembro de 1983, devido a novo ataque de E. atomaria, bastante severo, houve necessidade de controle químico.

QUADRO 1 - Porcentagem de área foliar comida por adultos de Epicauta atomaria (Germar, 1821) em plantas de Pithecellobium edwallii Hoehne, em quatro municípios do Estado de São Paulo, em 1982, num total de vinte observações em cada um deles

\begin{tabular}{|c|c|c|c|c|c|c|c|c|}
\hline \multirow{2}{*}{ Município } & \multicolumn{7}{|c|}{$\begin{array}{c}\text { Número de plantas nas classes de diferentes percentuais } \\
\text { de área foliar comida }\end{array}$} & \multirow{2}{*}{$\begin{array}{l}\text { Média } \\
\text { de área foliar } \\
\text { comida }\end{array}$} \\
\hline & $0 \%$ & $5 \%$ & $10 \%$ & $20 \%$ & $30 \%$ & $40 \%$ & $50 \%$ & \\
\hline & & & & & & & & $\%$ \\
\hline Olimpia & 0 & 0 & 1 & 4 & 8 & 4 & 3 & 32 \\
\hline Onda Verde & 0 & 1 & 5 & 8 & 5 & 1 & 0 & 20 \\
\hline Tanabi & 2 & 1 & 5 & 8 & 3 & 1 & 0 & 17 \\
\hline Pariqüera-açu & 3 & 0 & 3 & 6 & 6 & 2 & 0 & 20 \\
\hline
\end{tabular}

\section{SUMMARY}

DAMAGE CAUSED BY ADULTS OF EPICAUTA ATOMARIA (GERMAR, 1821) ON PITHECELLOBIUM EDWALLII HOEHNE PLANTS

A high infestation of adults of Epicauta atomaria (Germar, 1821) (Coleoptera: Meloidae) feeding on the foliage of Pithecellobium edwallii Hoehne was observed at the end of 1982 ip Olímpia, Onda Verde, Tanabi and Pariquera-Açu, all in São Paulo State, Brazil. Such leguminosae is utilized as a shade tree for the cacao crop. The defoliation was evaluated by visual estimation of the percentage of leaf area eaten. $P$. edwallii trees in Olímpia, Onda Verde, Tanabi and Pariqüera-Açu presented, respectively, the averages of $32,20,17$ and $20 \%$ of defoliation.

Index terms: Epicauta atomaria (Germar, 1821), Pithecellobium edwallï Hoehne, defoliation.

\section{REFERENCIAS BIBLIOGRAFICAS}

CORAL, F.J. \& BRILHO, R.C. Normas técnicas para o cultivo do cacaueiro. Campinas, Centro de Orientação Técnica, CATI, 1978. 6lp. 
GALLO, D.; NAKANO, O; SILVEIRA NETO, S.; CARVALHO, R.P.L.; BATISTA, G.C. de; BERTI FILHO, E.; PARRA, J.R.P.; ZUCCHI, R. A. \& ALVES, S.B. Manual de Entomologia Agrícola. Sã̀o Paulo, Ceres, 1978.531p.

MARICONI, F.A.M. Inseticidas e seu emprego no combate às pragas. São Paulo, Nobel, 1976. t.2.

\& ZAMITH, A.P.L. A "vaquinha" ou "burrinho" das solanáceas. O Biológico, São Paulo, 20(9):147-157, 1954.

MEDINA, J.C.; GARCIA, J.L.M.; LARA, J.C.C.; TOCCHINI, R.P.; HASHIZUME, T.; MORETTI, V.A. \& CANTO, W.L. do. Maracujá: da cultura ao processamento e comercialização. Campinas, Instituto de Tecnologia de Alimentos, 1980. 207p. (Série Frutos Tropicais, 9)

SILVA, A.G. d'A. e; GONÇALVES, C.R.; GALVÃO, D.M.; GONCALVES, A.J.L.; GOMES, J.; SILVA, M. do N. \& SIMONI, L. de. Quarto catálogo dos insetos que vivem nas plantas do Brasil, seus parasitos e predadores. Rio de Janeiro, Ministério da Agricultura, 1968. pt.2, t.1. 